\title{
Exploring Engagement Characteristics and Behaviours of Environmental Volunteers
}

\author{
Valentine Seymour and Mordechai (Muki) Haklay
}

\begin{abstract}
Environmental volunteering and environmental citizen science projects both have a pivotal role in civic participation. However, one of the common challenges is recruiting and retaining an adequate level of participant engagement to ensure the sustainability of these projects. Thus, understanding patterns of participation is fundamental to both types of projects. This study uses and builds on existing quantitative approaches used to characterise the nature of volunteer engagement in online citizen science projects, to see whether similar participatory patterns exist in offline environmental volunteering projects. The study uses activity records of environmental volunteers from a UK environmental charity "The Conservation Volunteers," and focuses on three characteristics linked to engagement: longevity, frequency, and distance travelled. Findings show differences in engagement patterns and contributor activity between the three UK regions of Greater London, Greater Manchester, and Yorkshire. Cluster analysis revealed three main types of volunteer engagement profiles which are similar in scale across all regions, namely participants can be grouped into "One-Session," "Short-Term," and "Long-Term" volunteer. Of these, the "One-Session" volunteer accounted for the largest group of volunteers.
\end{abstract}

Keywords: environmental volunteering; volunteer engagement; typologies; participatory patterns

\section{Introduction}

Environmental volunteering refers to the practice of unpaid volunteers spending time engaging in a wide range of practical conservation and outdoor-based activities, including pond weeding, dry stone walling, and coppicing trees (Bruyere and Rappe 2007). Examples include environmental volunteering or certain Non-Governmental Organisation (NGO) projects (e.g., the Burrenbeo Trust in Ireland). Environmental volunteering shares some parallels with environmental citizen science projects, as both engage members of the public in activities that help contribute to the conservation and restoration of natural environments (Roy et al. 2012). What distinguishes these two practices is the types of activities they engage in. Whilst in environmental citizen science projects volunteers typically collect data about the environment (e.g., number of species identified) in partnership with scientists, environmental volunteering project staff work with their volunteers to restore the environment through practical conservation activities (e.g., days spent coppicing trees).

Environmental volunteering and citizen science projects both play a pivotal role in civic participation and require

Department of Civil, Environmental and Geomatic

Engineering, University College London, Gower Street,

London WC1E 6BT, UK

Corresponding author: Valentine Seymour

(valentine.seymour.12@ucl.ac.uk) a continuity of volunteers to sustain their practices (Reed and Selbee 2001; Mohan and Bulloch 2012; Chu et al. 2012). For both types of projects, recruiting and retaining an adequate level of participant engagement to ensure long term sustainability of project activities is challenging (Hyde et al. 2016). Therefore, developing a volunteering or citizen science project that matches both the motivations and engagement levels of participants can be important for increasing and sustaining the level of long-term contribution (Chu et al. 2012).

The last 10 years have seen an increase in the use of computerised databases and online platforms by both environmental volunteering organisations and citizen science projects. For the context of this study, we first describe two broad types of computerised databases and online platforms used in citizen science projects-1) online and 2) information and communication technology (ICT)-dependent-and then compare them to databases used in environmental volunteering.

Online projects are those in which participants volunteer their efforts and abilities while working in networked environments on tasks that cannot exist offline (Liu and Ram 2011; Balestra et al. 2016). These projects are also known as "Citizen Cyberscience" (Grey 2009). Information on volunteers and their activities in these projects are recorded through their transaction log data as they engage directly with computerised databases and online platforms. Examples include Volunteer Thinking Citizen Science Projects (e.g., Snapshot Serengeti, Galaxy 
Zoo, Wikipedia), in which participants volunteer their cognitive abilities and classify information or images to help scientists and researchers solve research problems (Nov et al. 2011; Ponciano and Brasileiro 2014).

ICT-dependent projects are designed to actively involve volunteers in data collection as part of a scientific enquiry, using smartphones or an online system (Silvertown et al. 2015; Boakes et al. 2016). The volunteers might be in a situation where they have no Internet connection (e.g., in a remote location in a national park); in this case, the activity supports the recording of information offline which is later uploaded through the use of smartphones or websites, such as iSpot (Silvertown et al. 2015). Information about volunteers (e.g., identification codes) and their associated activities in these projects (e.g., data collected about species) is collected in a similar way to online projects, via online databases and mobile platforms. Examples include projects in which observers collect data to report on a local phenomenon which is then used for multiple purposes, including estimation of species trends or measurement of noiseand light pollution levels in different neighbourhoods. Like online projects, engagement patterns of those who volunteer in ICT-dependent projects can be analysed using a log of volunteers' activities.

By contrast, in environmental volunteering projects internally created online databases are used to manage volunteers' activities which all occur offline, and volunteers do not engage directly with ICT tools or the datacollection process. Information about volunteers (e.g., volunteering sites, regions, and projects attended) and their associated activities (e.g., number of days and tasks contributed) are collected by the project's staff and stored in an online database. Volunteer data collected are often used by project staff to report back to project funders to review volunteering project deliverables. Research that addresses participation in these projects has to date used national governmental surveys, which explore the total amounts of charitable giving and participation in civic engagement (Reed and Selbee 2001; Mohan and Bulloch 2012).

Using information collected about volunteers (e.g., identification codes) and their associated activities (e.g., tasks undertaken), researchers have begun to evaluate the activities of volunteers to identify participatory patterns in online and ICT dependent citizen science projects. One example found in citizen science research is Participatory Inequality, in which highly differentiated patterns of contribution are recognized amongst the volunteers (Nielsen 2006; Haklay 2016). Identifying volunteers' engagement characteristics and behavioural patterns has been achieved using both exploratory (graphic and non-graphic descriptive data summaries) and confirmatory (traditional statistical tools of inference, significance, and confidence) techniques. Such knowledge has been valuable in assisting practitioners in citizen science fields in their understanding, recruitment, and retention of individuals who engage in their activities. However, this remains an understudied area in volunteering research, with no studies to date using these approaches to characterise the nature of engagement in volunteering projects. Thus, knowledge about volunteering engagement would be considerably valuable in helping practitioners in the volunteering field in areas of project design and management.

This study applies and builds on existing quantitative approaches used to characterise the nature of volunteer engagement in online and ICT dependent projects. By using similar analytical methods, comparisons were made to identify whether similar participatory patterns exist in environmental volunteering projects. Despite differences in their activities, it is reasonable to expect that some parallels can be drawn between environmental volunteering and environmental citizen science projects, with each of these projects engaging members of the public in activities that help contribute to the conservation and restoration of natural environments. In particular, we explore the engagement characteristics and contributing behaviours of volunteers who engage in environmental volunteering activities managed by the UK charity, The Conservation Volunteers (TCVs), using volunteer data extrapolated from their online database. Described as one of the UK's largest environmental volunteering charities, TCV shares some similarities with online and ICT dependent citizen science projects in relation to the types of volunteer information data they collect (e.g., number of tasks completed).

\section{Characteristics of engagement in volunteer and citizen science projects}

In the last decade, the study of engagement has gradually emerged in both volunteering and citizen science research literature. The subject of engagement itself has been studied widely across other disciplines and includes user (Chapman 1997), work (Kahn 1990; Maslach 2011), and student engagement (Newmann 1992; Garrett 2011).

The term "engagement" has no generally agreed upon definition or conceptual framework. Instead, it is broadly defined and oriented towards the research field that is being studied. For instance, in studies on user engagement, the term has been defined loosely as "a process and product of interaction" in which its degree of intensity can alter with time depending on a host of factors, including attention, aesthetics, challenges, feedback, and motivation (O'Brien and Toms 2008). By contrast, work engagement centres on an employee's cognitive connection to their work and is said to be persistent in the event of challenges encountered. Within each of these study fields, there are two types of engagement: Attentional (intensity or degree of involvement and duration expenditure) and emotional (perception, motivation, cognitive, and experience) (Maslach 2011). In this study, we focus on attentional engagement, referred to here as the interaction or behaviour presented by a volunteer in relation to the project in which they engage. These behaviours can be used to understand a volunteers' level of engagement and are an area of limited yet valuable research amongst the volunteering sector with regards to volunteer recruitment and project management (Reed and Selbee 2001; Mohan and Bulloch 2012).

Often employed in user engagement research for website design, attentional engagement can be derived from a person's engagement characteristics (e.g., click-through 
rates, page views, and time spent on a website). These can be measured through a series of metrics (e.g., length, frequency, and geographical location of activity), with those characteristics being evaluated according to what information is obtainable or required. Researchers have begun using this approach to evaluate the attentional engagement of volunteers who engage in online and ICT dependent citizen science projects, using information collected about volunteers (e.g., identification codes and tasks contributed) via computerised databases and online platforms (Ponciano and Brasileiro 2014). A similar type of data about volunteers' attentional engagement is also being collected by some volunteering projects (e.g., TCV); these data have the potential to be used to characterise the nature of volunteer engagement within the volunteering sector.

This study used the following engagement characteristics: Longevity, frequency, and distance travelled. These characteristics were previously evaluated in online and ICT dependent citizen science projects (e.g., Tulloch and Szabo 2012; Ponciano and Brasileiro 2014; Boakes et al. 2016) and were selected for the current research owing to their importance to the sustainable management and design of environmental volunteering projects.

Longevity is the length of time that a person continues to be involved in volunteering and citizen science activities. Research has long shown much variation in the length of time that a person commits to engaging in volunteering and citizen science activities relating to a number of internal and external factors including intrinsic motivation, time availability, and type of volunteer project (Macduff 2005; Nov et al. 2011; Dunn et al. 2016). Understanding volunteers' longevity behaviours is important for overall project management in relation to the sustainability and continuity of their practices, adequacy of recruitment and retention, and the allocation of resources (e.g., equipment and training) (Nov et al. 2011; Chu et al. 2012).

Frequency refers to the regularity of a person's involvement in volunteering and citizen science activities. Online user engagement research commonly measures a person's level of involvement in an activity. The higher the involvement, the more engaged they are considered to be. This measurement is important from a project management perspective, particularly when planning for regular activities (e.g., weekly or monthly) or single events (Ponciano and Brasileiro 2014).

Finally, distance travelled measures the distance that a person travels to a volunteering or sample site from a starting location. In the context of this study, we refer to distance travelled as the distance that a volunteer travels to a volunteering project from their place of residence. Unlike most citizen science projects where volunteers can choose to do an activity either from home or in close proximity (depending on the project), environmental volunteering projects are organised group sessions that often occur for an entire day in set locations which require volunteers to travel. To date, no studies in volunteering research have looked into patterns of distances travelled; instead, they have identified the importance of distances travelled to a person's willingness to engage in environmental volunteering activities (Pope 2005; O'Brien et al. 2008; Tulloch and Szabo 2012). Potential barriers include insufficient public transport, car accessibility, and reimbursement of transport costs (Pope 2005; Tulloch and Szabo 2012). Nonetheless, such knowledge is of particular importance to project managers in both environmental volunteering and citizen science projects to assist in identifying funds for volunteers' travel reimbursement, selecting locations to hold volunteering sessions or data collection surveys, and to organise travel arrangements if required (e.g., minibus or car sharing).

\section{Related work and existing gaps in knowledge}

Characterising volunteer's motivations that can underlie their engagement has a wide literature base in volunteering and citizen science research, examining both qualitative (e.g., questionnaires) and quantitative dimensions (e.g., measurement indexes). Previous research has touched on many areas including motivations to volunteer (Clary and Snyder 1999); the linkage between volunteer role and self-identity (Stryker 1980); comparing the relationship between volunteer motivation and project contributions (Nov et al. 2011; Balestra et al. 2016); individual trait-based characteristics of those who choose to volunteer (Davis Smith 2005); and task or activity preferences (Willems and Walk 2013). Studies have revealed how factors of personality characteristics, team affiliation, social enjoyment, types of volunteering projects, current life situations, and personal motivations can predict a person's initial and ongoing involvement in volunteering activities. Yet, whilst these findings provide useful insights into volunteers' underlying motivations for project engagement, more research is needed which focuses on project management and adaptability to levels of volunteer retention in order to help strengthen their practices. This is particularly important in volunteering fields where empirical research has been limited.

Studies in volunteering research which have focused on the engagement behaviours of volunteers include exploring the total amounts of charitable giving, volunteering and participation in civic engagement, and analysing associations between civic engagement and religiosity (Reed and Selbee 2001; Mohan and Bulloch 2012). Quantitative methods used in each of these volunteering studies were descriptive (e.g., percentage proportions and total counts) and derived from governmental surveys based on subsamples of the national population. In each of these studies researchers found that few volunteers contributed the majority of UK volunteering activities, findings that resonate closely with patterns of participatory inequalities identified amongst online and ICT dependent citizen science projects (Haklay 2016). Further, the study of Mohan and Bulloch (2012) which explored the socio-demographic backgrounds of highly contributing volunteers found that they were largely from prosperous, middle-aged, and highly educated sections of the UK population. However, findings from volunteering studies remain largely generalised in scope and have not yet fully explored the different types of volunteer engagement characteristics or volunteering projects, nor have they 
cross-examined these patterns amongst urban-rural population density distributions. Such knowledge would help to identify variability in volunteers' engagement patterns as well as any relating factors (e.g., level of engagement, type of volunteering project, and transport mobility).

Research on engagement behaviours of volunteers also has emerged in the field of human computation, in particular Volunteer Thinking projects (e.g., Zooniverse, SETI@ home, and The Milky Way Project). Existing studies in this area include analysing the contributing activity of volunteers (Neis and Zipf 2012), understanding volunteers' recording behaviours in species monitoring (Boakes et al. 2016), characterising volunteer engagement (Tulloch and Szabo 2012; Ponciano et al. 2014), and volunteer engagement profiling (Ponciano and Brasileiro 2014). The studies use various quantitative analytical approaches (e.g., descriptive statistics and cluster analytical approaches) to evaluate the activity logs of volunteers who engage in online and ICT dependent citizen science projects. These studies reveal how these analytical approaches can be used to identify volunteers' contributing behaviours and engagement patterns in these projects. For instance, Ponciano and Brasileiro (2014) used a clustering analytical approach to identify engagement profiles of volunteers, grouping volunteers according to similarities and dissimilarities between their engagement characteristics. This inductive analytical inquiry is a commonly used technique for classifying information data into categories or groups that share similar characteristics and is used where no previous knowledge of these categories or groupings exists. Whilst the analytical approaches in these studies have been used to explore citizen science projects specifically, there is scope for these methods to be applied in other related or nearby fields (e.g., volunteering) that wish to explore people's engagement for project management purposes.

\section{Methodology}

To examine the engagement characteristics and profiles of those involved in environmental volunteering, we used descriptive and cluster analytical approaches, implementing significance testing where possible. These analytical approaches were conducted from June to December 2015 to assess the characteristics (e.g., longevity) that form the basis of volunteers' engagement profiles using information from the UK environmental charity, The Conservation Volunteers (TCV).

\section{Data Source}

Described as one of the UK's largest environmental volunteering charities, TCV has engaged people from diverse backgrounds and abilities who have taken part in various practical conservation projects since it was established in 1959. In this study, we focus on the charity's larger and more well-known projects, the Action Teams. This project was established when the charity was initially set up and engages environmental volunteers in practical conservation work, including pond weeding, dry-stone walling, and coppicing trees. Despite differences in types of activities, environmental volunteering projects share goals with many environmental citizen science projects, as each engage members of the public in activities that help contribute to the conservation and restoration of natural environments (Roy et al. 2012). TCV was selected as a case study project to identify whether participatory patterns in environmental citizen science projects exist in environmental volunteering projects. Findings observed in this study may be applicable to both environmental volunteering and citizen science projects in areas of project design and management.

In 2001, the charity was one of the first in its field to develop an online database initially as a simple volunteering tracking system in Northern Ireland. Its information functionality and requirements have been shaped by TCV's management approach and work context. Since then, the database has evolved into a complex national volunteer project management tool, storing a total of 222,605 records of volunteers who collectively have undertaken 241,990 conservation tasks over 12 UK geographical regions. The information in the system was collected by TCV staff using both paper and online forms to record volunteer's information (e.g., socio-demographics, TCV sites, regions, and projects attended) as well as their activities (e.g., number of days and conservation tasks contributed) usually after the activity ended. Much of the data collected about volunteers and their activities are similar to the types of volunteer data collected in online and ICT dependent citizen science projects.

To calculate the characteristics (longevity, frequency, and distance travelled) previously identified as being important for measuring engagement patterns in environmental volunteering projects, we selected the following data items: Volunteer identification code, region identification, site identification, total active days, start and end dates of volunteering, and postcodes of volunteer's places of residence and TCV sites attended. This enabled us to explore engagement characteristics and contributing behaviours of volunteers who engaged in TCV projects. Further, due to the scale and volume of volunteer records, the study was based on all volunteers registered from January 2010 to December 2013.

The analysis focused on the following volunteering regions: Greater London $(\mathrm{n}=6690)$, Greater Manchester $(n=810)$, and Yorkshire $(n=2871)$. We analysed these three regions to identify any influences of population density distributions in rural (e.g., Yorkshire) to urban areas, differences in mobility potential (e.g., public transport services), and as cross-examination between relatively similar urban regions (e.g., Greater London and Manchester). All volunteer information was both confidential and anonymised in line with ethical practices and a data sharing agreement with TCV. No personal or sensitive information was used in the analysis, including gender, ethnicity, and economic status.

\section{Data analysis}

Data analysis consisted of two main parts; first, engagement characteristics and contributor activity, and second, volunteer engagement profiles. All statistical analysis was 
performed using R Version 3.1.1 (R Core Team 2014) and all spatial analysis was conducted using ArcGIS (Version 10.1).

Engagement characteristics and contributor activity of volunteers was identified and assessed as follows. First, exploratory data analysis, both graphical (bar graphs) and non-graphical (descriptive tables, ratio proportions, and percentages) was used to reveal and visually represent the underlying features of the dataset in relation to the following: Numbers of volunteers, net annual changes in volunteer numbers, length of time volunteering, number of volunteering sessions attended, number of days between sessions, proportion of "One-Session" to "Multi-Session" types of volunteers, and their individual contributions to overall volunteering activities. Second, confirmatory data analysis was used to assess relationships and differences among geographical regions, year of analysis, and TCV sites. This was carried out using a series of 2-Way ANOVA (with replication) statistical tests on the following data information (Dytham 2011); volunteering numbers and number of volunteering sessions (also referred to as activities).

Volunteer engagement profiles were identified using engagement metrics and clustering algorithms described by Ponciano and Brasileiro (2014), which analysed engagement patterns of those who participated in Volunteer Thinking projects that are part of the Zooniverse. Unlike Ponciano and Brasileiro's (2014) analysis, the current study includes volunteers who attended only one volunteer session. This was to ensure both a full analysis of all volunteers who "engage" in volunteering activities and that their engagement characteristics could be made and understood (Rochester 2006).

Three of the four engagement characteristics defined by Ponciano and Brasileiro (2014) were used: Activity Ratio, Relative Activity Duration, and Variation in Periodicity. Such characteristics are particularly useful for understanding a volunteer's level of productivity, attendance frequencies, and length of time spent volunteering. Activity Ratio is the number of days that a volunteer was active divided by the total days they are linked to the volunteering project, i.e., all of the days between the first and last days of engaging in volunteering activities. A volunteer was considered to be active if they attended at least one session. Relative Activity Duration is the ratio between the numbers of days that a volunteer was active divided by the overall study observation period in days. Finally, Variation in Periodicity is the average number of days elapsed between two sequential days that an individual was active divided by the total average number of days elapsed between active days of all individuals. Engagement metrics were then normalised to span 0 to 1 using the following normalisation scaling formula where $x$ is the engagement metric and $i$ is the volunteer:

$$
X_{i=\frac{x_{i}-x_{\min }}{x_{\max }-x_{\min }}}
$$

In addition to the three engagement characteristics outlined above, distances travelled by volunteers was included in the engagement profiling method. This was calculated using ArcGIS. Volunteer's place of residence and TCV sites were first geocoded using Code-Point ${ }^{\circledR}$ Open dataset and ESRI's World Street base map data. As 2,896 (27.9\%) of volunteer postcodes for their places of residence were either missing or incorrect, the analysis was based on a total of 7,475 volunteers for the three regions, Greater London ( $n=4887)$, Greater Manchester $(n=624)$, and Yorkshire $(\mathrm{n}=1964)$. Using OS Master Map ${ }^{\circledR}$ Integrated Transport Network Layer dataset (Version 09/2015), we calculated the shortest distance (in miles) between each volunteer's places of residence and TCV volunteering sites, approximating the distance travelled by volunteers using the shortest route between locations inclusive of roads (Zhu et al. 2013). This ensured a higher degree of accuracy than the Euclidean (straight line) distance, taking account for actual street network structures (e.g., bridges, rivers, and road networks) that can affect volunteer's distances travelled and time investment (Nicoară and Haidu 2014). This is particularly important in London, where a short distance across the river can be translated to a much longer travel time on the road, due to the limited number of bridges.

Following this, we identified behavioural profiles of volunteers who exhibited similar engagement characteristics using a clustering analytical approach (Ponciano and Brasileiro 2014). This inductive analytical inquiry is a commonly used technique for classifying information data into categories or groups that share similar characteristics, and is used where no previous knowledge of these categories or groupings is available. First, the hierarchical cluster analysis using the R package "cluster" (Maechler et al. 2015) was applied to understand the grouping of volunteers using Ward's Minimum Variance method to estimate the observed similarities and dissimilarities between volunteer's engagement metrics. This enabled the datasets to be organised into distinguishable grouped clusters where no predefined number had been selected (Fielding 2007). Drawing on this, the within-group sum of squares by the number of clusters for each dataset region was then plotted to identify the number of grouped clusters. K-Means clustering approach was then applied to partition data points into the $k$ number of groupings selected, which sorted data values according to the nearest mean at each cluster's centre (Wagstaff et al. 2001). An Averaged Silhouette Width (Hennig 2015) was then used to validate the numbers of clusters selected and evaluate each cluster's degree of tightness and separation (Rousseeuw 1987). Those scores equal to or larger than 0.51 were used as a reference to indicate sufficient partitioning. In addition, Spearman's rank correlation coefficients were used to observe whether relationships could be identified between each of the engagement metrics that would further explain volunteer engagement profiles.

\section{Results \\ Volunteer characteristics: Total volunteering numbers and retention levels}

We calculated the total numbers and retention levels of TCV volunteers from January 2010 to December 2013 (See Table 1). First, the total number of volunteers from each of the three geographical regions varied widely. Greater London presented the highest overall volunteer 
population (2539 to 724 ) by comparison to Greater Manchester (237 to 178) and Yorkshire (907 to 592). From this, the percentage of each region's volunteering population size relative to the TCV's overall volunteering population (6989 to 3693) was calculated as follows; Greater London (19.6-36.3\%), Greater Manchester (2.7-4.8\%) and Yorkshire (10.8-16\%). Further, there were no stable trends in volunteering numbers across sites, instead they were quite variable. Similarly, there were no differences in volunteering numbers between months throughout the year.

Volunteers' yearly retention levels differed across each region presenting no clear trends. In general, volunteering numbers increased from 2010 to 2012, with decreases occurring across all regions between 2012 and 2013. The Greater London region accounted for most of these yearly changes in volunteering numbers, having the highest retention levels. By comparison, Greater Manchester and Yorkshire have lower retention levels.

In summary, there were no clear trends in volunteer numbers across all three regions, both yearly and between individual volunteering sties. Greater London exhibited the highest volunteer population and retention levels, compared to the other two regions. Further, seasonal variability shows no bearing on volunteer numbers, with the volunteering site having more of an impact.
Volunteer characteristics: Longevity, frequency, and distance travelled

We calculated the total length of time that volunteers were actively engaged (longevity) in volunteering activities as well as the number of volunteering sessions they attended (frequency) for each region. The total length of time that volunteers were actively engaged varied from 1 day to up to 3 years. We also observed differences in the number of sessions that volunteers attended and the amount of time that lapsed between these sessions. Overall, findings showed similar trends in longevity and frequency characteristics across all geographic regions (See Figures 1 and 2), with a higher number of volunteers engaging in one volunteering session.

Ratio proportions of "One-Session" to "Multi-Session" volunteers varied. The overall value for the UK was 18:7, which differed from Greater London (5:1), Greater Manchester (3:2), and Yorkshire (1:1). Overall, participatory patterns across all regions revealed that a small percentage of "Multi-Session" volunteers contributed the most to volunteering activities, with a larger proportion of "OneSession" volunteers contributing the least. For instance, of the 207,671 total volunteering activities for all UK regions (Table 2), 89.1\% were conducted by "Multi-Session" volunteers, who make up $27.6 \%$ of the total volunteers. This participatory pattern of "Multi-Session" volunteers

Table 1: TCV's annual volunteer numbers between years 2010 to 2013 for each geographical area.

\begin{tabular}{lrrrr} 
& Total UK & Greater London & Greater Manchester & Yorkshire \\
\hline Mean & 5692 & 1673 & 203 & 718 \\
Medium & 6042 & 1716 & 198 & 686 \\
$1^{\text {st }}$ Quartile & 4861 & 1403 & 184 & 606 \\
$3^{\text {rd }}$ Quartile & 6873 & 1986 & 216 & 797 \\
SD & 1547 & 744 & 26 & 147 \\
Range & 6989 & 2534 & 237 & 907
\end{tabular}

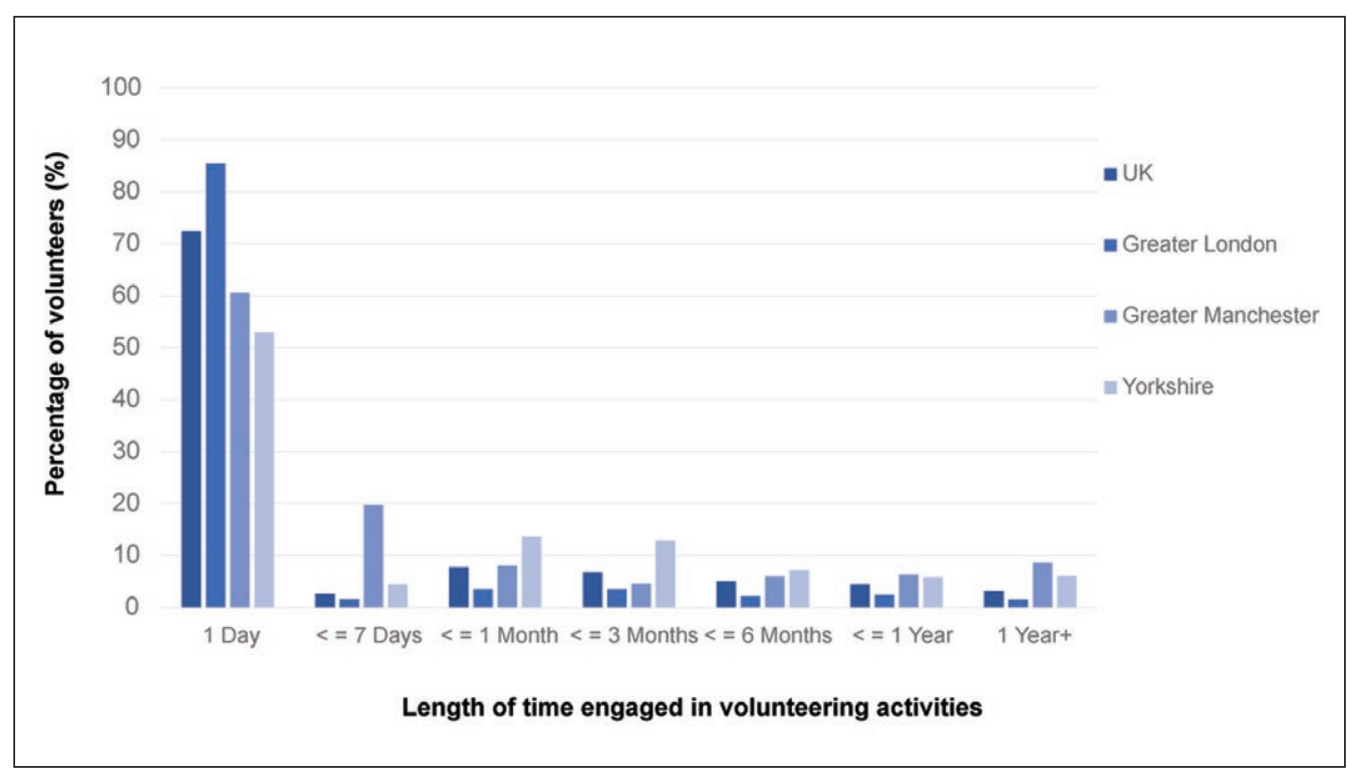

Figure 1: Total percentage of TCV volunteers' length of time volunteering. 


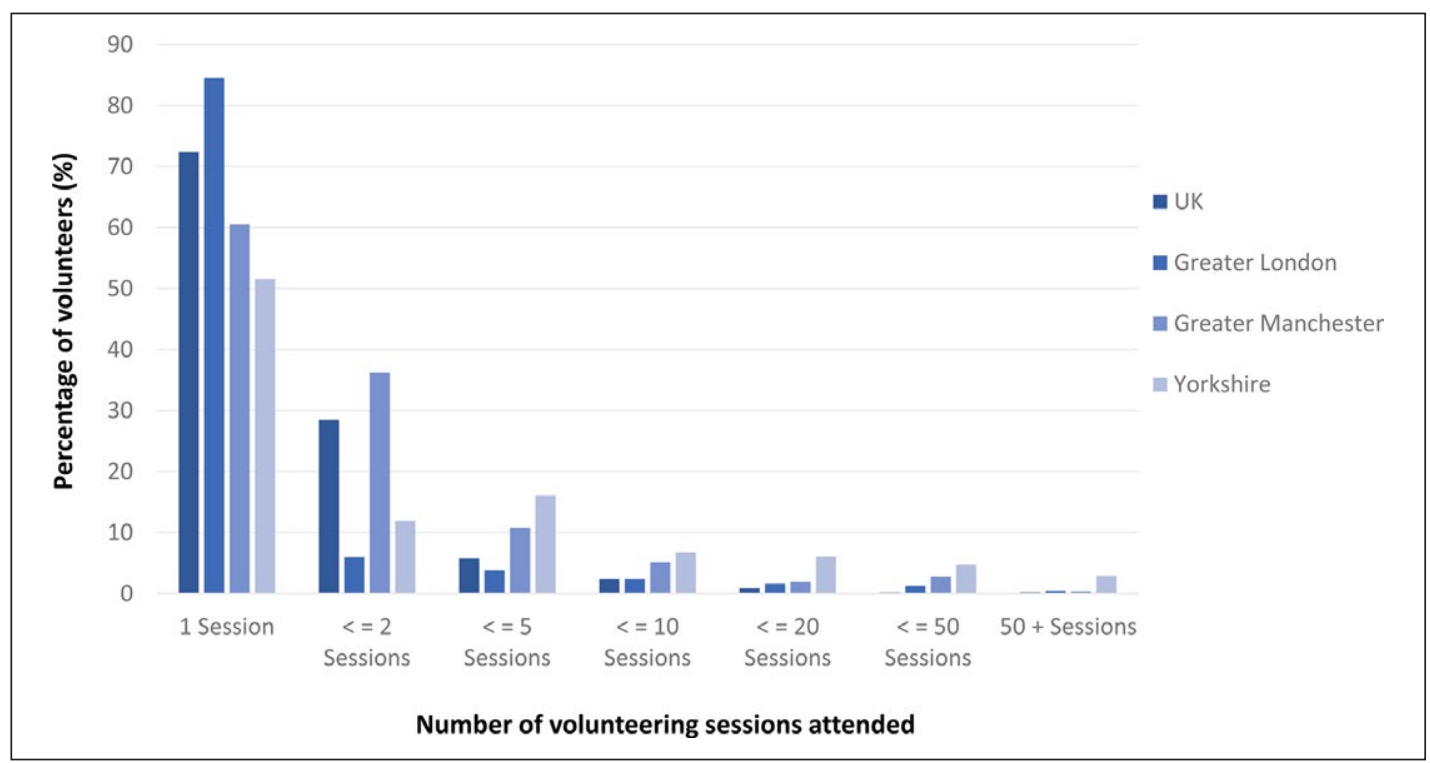

Figure 2: Total percentage of TCV volunteers attending volunteering sessions.

Table 2: Annual volunteering activities for each geographic area.

\begin{tabular}{lrrrr} 
Regions & $\mathbf{2 0 1 0}$ & \multicolumn{1}{c}{$\mathbf{2 0 1 1}$} & $\mathbf{2 0 1 2}$ & $\mathbf{2 0 1 3}$ \\
\hline Greater London & 3372 & 5467 & 5160 & 7386 \\
Greater Manchester & 1552 & 1282 & 1610 & 1920 \\
Yorkshire & 4332 & 4190 & 7073 & 7053 \\
Total UK Activities & 43187 & 49734 & 56420 & 58330
\end{tabular}

is similar across each of the regions: in Greater London $11.1 \%$ of volunteers contributed $95.6 \%$ of activity, while in Greater Manchester 39.5\% contributed 80.4\% of activity, and in Yorkshire 33\% contributed $96.7 \%$ of activity.

Findings showed that the numbers of volunteers decreased with increasing distances travelled. These trends were replicable between both "One-Session" and "Multi-Session" volunteers, with the majority living within a 20-mile distance of the TCV site they attended. Overall estimated distances travelled by volunteers for each region were as follows: Greater London about 32 miles, Greater Manchester about 36.5 miles, and Yorkshire about 42.3 miles. Findings also showed that in the two urban regions most volunteers (Greater London 79.9\%, Greater Manchester $85.56 \%$ ) lived within a 5 to 20 -mile distance from the TCV site they attended. By contrast, most volunteers (62.05\%) in Yorkshire lived within close proximity of up to 5 miles from the TCV sites they attended. These findings were consistent whether a volunteer attended one or multiple sessions, as illustrated in Table 3.

To summarise, similar trends were observed in longevity and frequency characteristics across all geographic regions, with a large proportion of volunteers engaging in one volunteering session. Additionally, participatory patterns across all regions revealed that a small percentage of volunteers contributed the most to volunteering activities, with a larger proportion contributing the least. Finally, most volunteers lived within a commutable distance of the TCV site they attended, with few travelling from farther distances.

\section{Volunteer engagement profiles}

A clustering analytical approach identified engagement profiles of volunteers, grouping volunteers according to similarities and dissimilarities between their engagement characteristics. This analytical approach revealed three distinguishable profiles of volunteers termed as One-Session, Short-Term, and Long-Term. These were shown to be the number that best optimised the trade-offs between the number of groups and the within-group sum of squares. This was validated in Averaged Silhouette widths, with scores above 0.51 indicating sufficient partitioning of the clustered groupings (Greater London 0.58; Greater Manchester 0.55; Yorkshire 0.57). The general descriptives of the three regions' engagement metrics subdivided into profile types as defined by Ponciano and Brasileiro (2014) are shown in Table 4.

In general, the average number of days that volunteers were active during the time they volunteered (Activity Ratio) were moderate to high across all regions, as indicated in means, medians, and quartiles. The length of time that volunteers actively engaged in environmental volunteering activities (Relative Activity Duration) tended to be longer in Greater Manchester, with a higher proportion volunteering for a short duration. Further, the number of days elapsed between each volunteering session 
(Variation in Periodicity) shows a slight variability between regions, as indicated in the range. For instance, volunteers in Yorkshire attended sessions less frequently than did volunteers in urban regions (e.g., Greater Manchester). In addition, the mean average distance travelled is relatively similar across each region, with most volunteers living within a proximity of up to 10 miles to the TCV sites they attend.

Volunteer's engagement profiles (see Table 5) are as follows:
One-Session volunteer: These volunteers account for the largest proportion of the volunteer population, travelling the least distance and committing the shortest amount of time.

Short-Term volunteer: These volunteers had a profile type mid-way between the other two.

Long-Term volunteer: These volunteers represented the smallest proportion of the volunteering population, travelling the farthest distance and committing the longest amount of time to the organisation.

Table 3: Volunteer travelling distances in percentage across the three geographical regions for each volunteer type.

\begin{tabular}{llrrrrrr} 
Volunteer Type & Regions & \multicolumn{7}{c}{ Distance Travelled (\%) } \\
\cline { 3 - 8 } & & $<=\mathbf{1}$ Mile & $<=\mathbf{5}$ Miles & $<=\mathbf{1 0}$ Miles & $<=\mathbf{2 0}$ Miles & $<=\mathbf{3 0}$ Miles & $\mathbf{3 0 +}$ Miles \\
\hline \multirow{2}{*}{ One-Session } & Greater London & 3.3 & 28.4 & 29.4 & 30.9 & 7 & 0.9 \\
& Greater Manchester & 2.3 & 27.8 & 39.7 & 20.7 & 7.9 & 1.6 \\
& Yorkshire & 8.2 & 52.9 & 19.7 & 13.6 & 4.5 & 1.6 \\
\multirow{3}{*}{ Multi-Session } & Greater London & 9.9 & 61.5 & 20 & 6.2 & 1.9 & 0.3 \\
& Greater Manchester & 1.2 & 24.1 & 50.6 & 20.7 & 4.1 & 1.2 \\
& Yorkshire & 14.8 & 53.8 & 14.9 & 9.4 & 5.7 & 1.2
\end{tabular}

Table 4: General descriptions for each of the engagement characteristics (Activity Ratio [AR], Relative Activity Duration [RAD], Variation in Periodicity [VP], and Distance Travelled in miles [Distance]) compared across each region.

\begin{tabular}{lrrrrrrrrrrrr} 
& \multicolumn{4}{c}{ Greater London } & \multicolumn{4}{c}{ Greater Manchester } & \multicolumn{3}{c}{ Yorkshire } \\
\cline { 2 - 13 } & AR & RAD & VP & Distance & AR & RAD & VP & Distance & AR & RAD & VP & Distance \\
\hline Mean & 0.8 & 0.02 & 0.6 & 8.7 & 0.63 & 0.04 & 0.9 & 6.1 & 0.7 & 0.07 & 1 & 8.8 \\
Medium & 1 & 0.05 & 0.8 & 3.3 & 1 & $<0.01$ & 0.05 & 7 & 1 & $<0.01$ & 0.09 & 3.5 \\
$1^{\text {st }}$ Quartile & 0.04 & 0.01 & 0.4 & 1.9 & 0.14 & $<0.01$ & 0.05 & 4.7 & 0.13 & $<0.01$ & 0.09 & 1.8 \\
$3^{\text {rd }}$ Quartile & 1 & 0.02 & 2 & 8.9 & 1 & 0.03 & 0.3 & 11.2 & 1 & 0.03 & 0.7 & 6.6 \\
SD & 0.3 & 0.09 & 2.7 & 6.7 & 0.4 & 0.1 & 3.1 & 7.2 & 0.4 & 0.2 & 2.7 & 6.6 \\
Range & 1 & 1 & 34 & 32 & 1 & 1 & 41 & 42.3 & 1 & 1 & 19.4 & 36.5
\end{tabular}

Table 5: Mean centroids for each of the engagement characteristics (Activity Ratio [AR], Relative Activity Duration [RAD], Variation in Periodicity [VP] and Distance Travelled in miles [Distance]) compared across each region and subdivided by profile type.

\begin{tabular}{llrrrr} 
Profile Type & Regions & \multicolumn{4}{c}{ Engagement Characteristics } \\
\cline { 3 - 6 } & & AR & RAD & VP & Distance \\
\hline \multirow{2}{*}{ One-Session } & Greater London & 0.97 & 0.01 & 0.8 & 4.6 \\
& Greater Manchester & 1 & $<0.01$ & 0.4 & 3.5 \\
& Yorkshire & 0.88 & 0.02 & 0.7 & 2.4 \\
\multirow{5}{*}{ Short-Term } & Greater London & 0.9 & 0.02 & 0.4 & 8.9 \\
& Greater Manchester & 0.88 & 0.5 & 1 & 11.6 \\
& Yorkshire & 0.78 & 0.04 & 0.9 & 6.2 \\
& Greater London & 0.8 & 0.03 & 0.6 & 28.3 \\
& Greater Manchester & 0.68 & 0.77 & 1.1 & 30.1 \\
& Yorkshire & 0.61 & 0.05 & 1.8 & 35.9
\end{tabular}


Regions differed in engagement characteristics. In general, activity ratios were relatively similar in Greater London and Manchester, with volunteers being active for shorter periods than those in Yorkshire. Marked differences were also observed in the time elapsed between the number of volunteering sessions attended (periodicity) by volunteers as well as in their distances travelled. This suggests that each of the profile types have a variable range with noticeable distinctions between those more urbanised regions (e.g., Greater London and Manchester) to those semi-urban and rural (e.g., Yorkshire). Further, there is a noticeable gradient in engagement metrics across each engagement profile. This is supported by a series of Spearman's rank correlation coefficient (as data presented a non-normal distribution) where a statistical significance was observed between each of the four engagement metrics $(\mathrm{p}<0.001)$.

Numbers and percentages of volunteers classified in each engagement profile grouping are shown in Figures 3 and $\mathbf{4}$. One-Session volunteers make up the largest group of volunteers, with Long-Term volunteers being the smallest, and this pattern is present across all regions.

In summary, there were clear distinctions between those more urbanised regions to those semi-urban and rural, with volunteers from urban regions (e.g., Greater London) being more actively engaged in volunteering activities for longer periods than those in semi-urban and rural areas (e.g., Yorkshire). Further, we identified three types of volunteer engagement profiles that are similar in scale across all regions. Volunteer engagement profiles presented a distinct gradient in their engagement characteristics, with "One-Session" and "Long-Term" being on opposite ends of the spectrum.

\section{Discussion}

Overall, this study demonstrates that descriptive and clustering analytical approaches used to characterise the nature of volunteer engagement in online and ICT

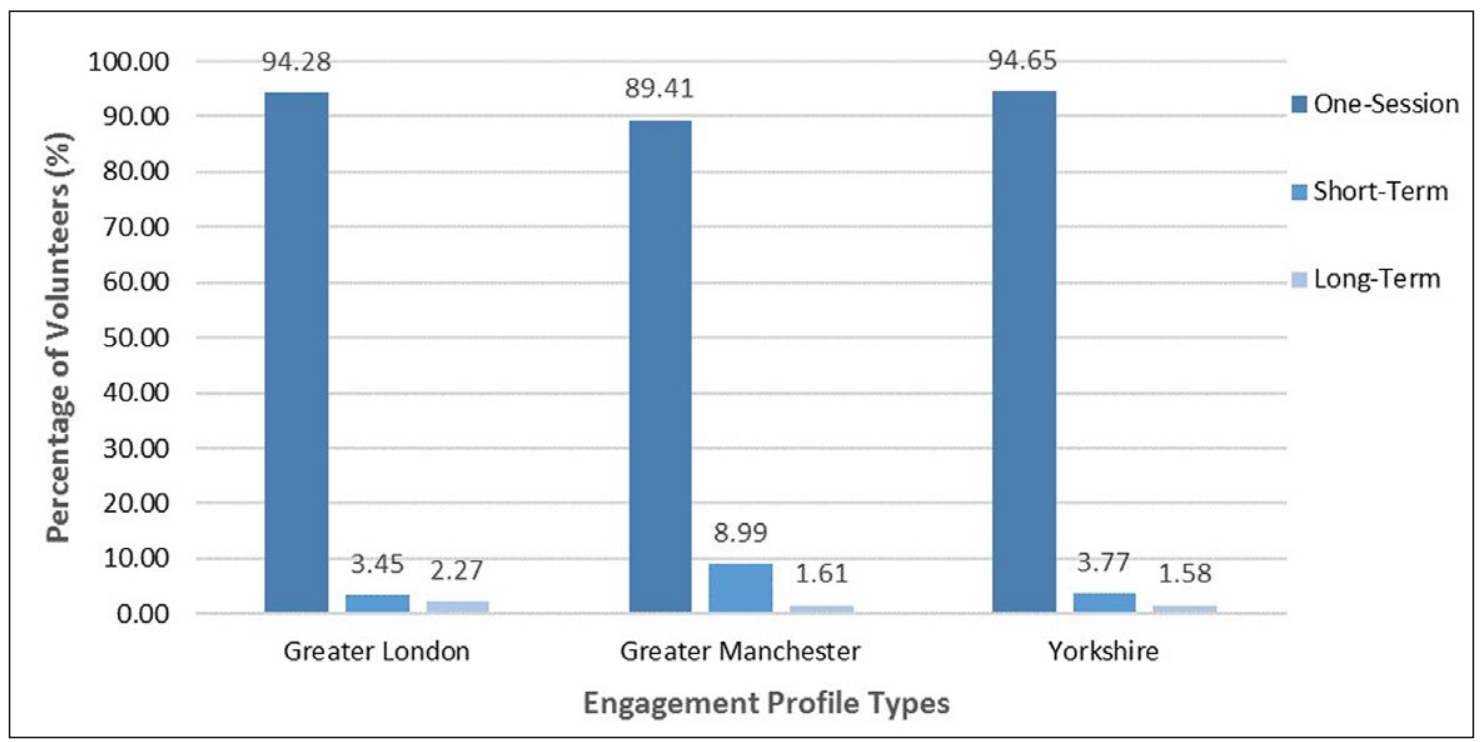

Figure 3: Percentage proportions of volunteers who contribute to each engagement profile type across regions.

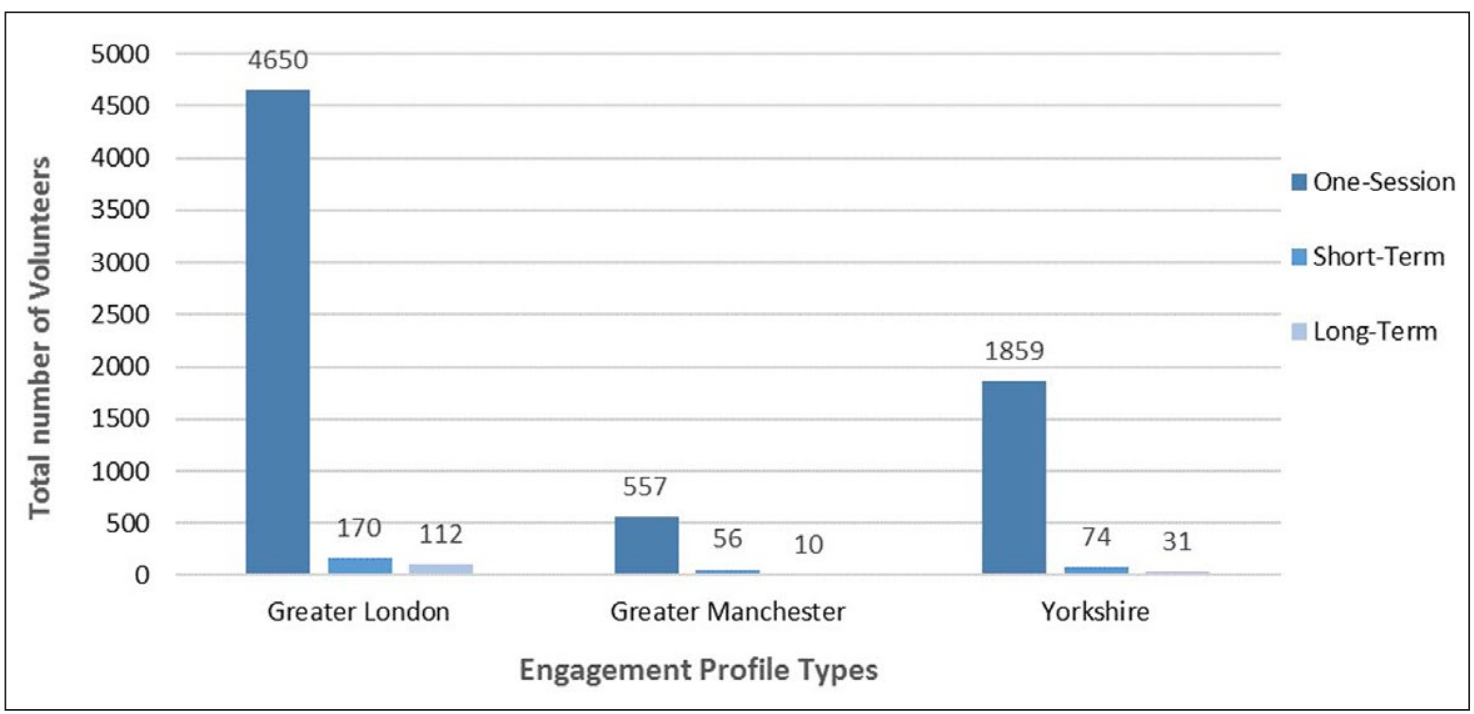

Figure 4: Total numbers of volunteers who contribute to each engagement profile type across regions. 
dependent projects were applicable to TCV's volunteering dataset. Comparisons could be made to identify whether similar participatory patterns (e.g., Participatory Inequality) exist in environmental volunteering projects, discussed further below. In addition, this study showed the potential for alternative measures of volunteer's engagement (e.g., distances travelled) to be incorporated into future assessments, both in environmental volunteering and citizen science projects. Such analytical approaches could therefore be viewed as valuable in assisting practitioners in both environmental volunteering and citizen science fields in their understanding, recruitment, and retention of individuals who engage in their activities. Knowledge gained from this analytical approach could help to increase long-term sustainability and design of environmental volunteering and citizen science projects and bring them in alignment with volunteer's engagement typologies and overall participatory patterns (Chu et al. 2012).

Our findings presented differences in yearly retention levels and longevity behaviours of volunteers between the three UK regions examined. Of these, Greater London exhibited both a higher volunteer population as well as those engaging in volunteering activities over a longer duration. Several factors might explain this trend, including population density, social factors, and project organisation (Ryan et al. 2001). By understanding volunteers' population size and longevity behaviours, project staff overseeing environmental volunteer and citizen science projects can be better equipped in organising resources required (e.g., equipment) as well as planning which tasks to undertake and how many (e.g., practical conservation activities and data collection), thus strengthening the continuity of their practices.

In relation to the ratio proportions of "One-Session" and "Multi-Session" volunteers and their associated contributions to volunteering activities, a common trend was identified across all regions in which a few volunteers contributed the most and many volunteers contributed the least, demonstrating that "participation inequality" is happening in environmental volunteering as well as in citizen science projects and online web platforms, e.g., OpenStreetMap and Wikipedia (Liu and Ram 2011; Neis and Zief 2012; Tulloch and Szabo 2012; Ponciano and Brasileiro 2014). This suggests that participation inequity is present not only in online social media or citizen science initiatives but also in offline environmental volunteering projects. Such information is important for the project management of environmental volunteering and citizen science projects and can be useful in relation to planning the frequency of sessions (e.g., weekly or monthly) and the type or length of time allocated to a task (e.g., single event or ongoing project) (Ponciano and Brasileiro 2014).

Considering the distance travelled in both environmental volunteering and environmental citizen science projects, our findings showed that the majority of volunteers lived within a 20-mile distance of TCV sites, with fewer travelling farther distances. These trends were replicable between both "One-session" and "Multi-Session" volunteers, with slight noticeable differences between regions.
Similarly, the proportion of volunteers decreased with increasing distance travelled, with those in Yorkshire travelling farther than those in the other two regions. Possible explanations include the improved mobility potential in large urban areas such as public transport services (Pope 2005). In addition, vehicle ownership, financial resources, and the lower number of volunteering opportunities in areas with a lower population density can influence the distance travelled (O'Brien et al. 2008; Tulloch and Szabo 2012). Such knowledge can be valuable to project managers in both volunteering and citizen science projects when selecting locations to hold volunteering sessions or data collection surveys, and suggests the need to choose sites that maximise volunteer numbers for the purpose of the volunteering activity. Further, knowing how far volunteers travel to a site can assist project managers when allocating financial resources (e.g., travel reimbursement) as well as when organising travel arrangements (e.g., minibus or car sharing) for those travelling from farther distances, if required.

Volunteer engagement profiles were identified using a clustering analytical approach, grouping volunteers according to similarities and dissimilarities between their engagement characteristics. Such an approach is commonly used where, as in this study, no previous knowledge of these categories or groupings existed. This approach indicated there to be three main profile types of similar scale across all three regions; "One-Session," "Short-Term," and "Long-Term." This suggests general consistency in profile types with no marked regional variation similar to those identified in related studies. We will now summarise these profiles more fully.

First, "One-Session" volunteers account for the largest group, travelling the least distance and committing the shortest amount of time. Findings concur with similar studies in existing citizen science (e.g., Boakes et al. 2016) and volunteering projects (e.g., Holmes 2014; Hyde et al. 2016), providing further evidence on the emerging shift in engagement patterns towards those more casual and episodic (Rochester 2006). Suggested explanations for this trend include time availability and motivations (Clary and Snyder 1999; Davis Smith 2005; Rochester 2006; Balestra et al. 2016).

Second, those classified as "Short-Term" have a profile type mid-way between "One-Session" and "Long-Term." This transition was also identified by Cnaan and Amrofell (1995) who suggested there to be no distinctions between volunteer typologies (e.g., one-off versus ongoing volunteer typologies). Instead they proposed a gradient or continuum of typologies, with those classified as episodic and casual-committing the least amount of time-being placed at the lower end of the spectrum. Very few studies (Rochester 2006; Ponciano and Brasileiro 2014) have described this profile type, placing more emphasis on those that are episodic or long-term. The "Short-Term" volunteer is a combination or overlap of the proceeding profiles by variable degrees, with further research still required.

Finally, those classified as "Long-Term" volunteers represented the smallest proportion, travelling the farthest 
distance and committing the longest amount of time to the organisation. These volunteers presented engagement characteristics that closely resemble those that have been described as the "classic" typology, who have a high level of unconditional dedication and a strong sense of affiliation with the organisation they volunteer with (Hustinx and Lammertyn 2003). Similar findings also have been identified in other studies (Boakes et al. 2016).

By understanding volunteers' engagement profiles, environmental and citizen science project staff can tailor their projects to meet both their project requirements (e.g., practical conservation tasks or data to be collected) and volunteers' level of engagement, which may help to increase volunteer participation. Further, a knowledge of how and in what ways volunteers engage in environmental volunteering and citizen science projects not only helps us to understand how these projects can increase their contribution to conservation and restoration of natural environments, it also increases our understanding of how these projects are important to people.

\section{Study limitations and future research}

We highlight the following issues for future research. First, though this study is able to characterise the nature of engagement in environmental volunteering projects, such quantitative analytical methodology fails to provide further contextual explanation behind these volunteers' patterns of engagement (e.g., motivations to volunteer). There is need to use complementary forms of qualitative methodological approaches (e.g., interviews and observations) in conjunction with quantitative approaches to provide a more in-depth understanding of volunteer engagement. Such mixed methods would allow for multiple perspectives, identifying not only the magnitude and frequency of volunteers' engagement patterns, but examining the meaning and understanding behind their occurrence (Bryman 2012).

Second, whilst figures calculated for volunteer's shortest distance travelled served as a good estimate of distances travelled, the study does not include the mode of transport. However, because findings suggest that distance travelled is associated with a volunteer's level of engagement, we recommend that future research implement these factors to ensure a more accurate assessment of volunteer's travelling distance.

Third, whilst engagement profiles were case specific to those that attended TCV, similar, more generalised findings on differentiated patterns of contribution also have been identified in existing volunteering research (Reed and Selbee 2001; Mohan and Bulloch 2012). This suggests that these findings could be extendable. Further work is needed to understand whether the profile types, scales (e.g., individual, regional, and national) as well as their proportional structures over time are attributable to other volunteer organisations. Further research also would provide a more in-depth understanding of volunteering typologies to help organisations adapt and accommodate their volunteering opportunities to existing trends in recruitment and retention.

\section{Conclusion}

This study demonstrates that the quantitative analytical approaches used to characterise the nature of volunteer engagement in online and ICT dependent projects were applicable to TCV's volunteering dataset. It also shows the potential for alternative measures of volunteer's engagement (e.g., distances travelled) to be used. These measures enabled comparisons to be made between environmental volunteering and citizen science projects to identify whether they shared any similarities in participatory patterns. Further, the study suggests potential for these methods to be applied in other fields wishing to explore people's engagement for project management purposes (e.g., volunteer retention and project design) if the relevant data are available.

The study also identifies areas that warrant more research. For example, we recommend that future research should implement additional forms of qualitative methods (e.g., semi-structured interviews and observational studies) to explore contextual information associated with volunteers' engagement patterns, including underlying motivations. In addition, the study opens questions about whether the profile types as well as their proportional structures over time are attributable to other volunteer organisations. Such evidence would provide a more holistic and realistic perspective of our existing knowledge and understanding of engagement presented by volunteers.

\section{Acknowledgements}

This study was sponsored by University College London and The Conservation Volunteers. Volunteer information data in this study was kindly provided by The Conservation Volunteers. The authors would like to thank the following people for their advice and comments during the writing of this manuscript: Dr Fakhar Khalid, Mike Wood, and Liam Grove.

\section{Competing Interests}

The authors have no competing interests to declare.

\section{References}

Balestra, M., Arazy, O., Cheshire, C. and Nov, O., 2016. Motivational determinants of participation trajectories in Wikipedia. In: Proceedings of the 10th International Conference on Weblogs and Social Media (ICWSM 2016), Cologne, Germany on October 30-November 3 2016.

Boakes, E.H., Gliozzo, G., Seymour, V., Harvey, M., Smith, C., Roy, D.B. and Haklay, M., 2016. Patterns of contribution to citizen science biodiversity projects increase understanding of volunteers' recording behaviour. Scientific Reports, 6(33051). DOI: https://doi.org/10.1038/ srep33051

Bruyere, B. and Rappe, S., 2007. Identifying motivations of environmental volunteers. Journal of Environmental Planning and Management, 50(4): 503-515. DOI: https://doi.org/10.1080/09640560701402034

Bryman, A., 2012. Social science research methods. $4^{\text {th }}$ edition, Oxford: OUP Oxford. 
Chapman, P., 1997. Models of engagement: Intrinsically motivated interaction with multimedia learning software. Unpublished Master's Thesis. University of Waterloo, Waterloo, Canada.

Chu, M., Loenard, P. and Stevenson, F., 2012. Growing the base for citizen science: Recruiting and engaging participants. In: Dickinson and Bonney (eds.), Citizen Science: Participation in Environmental Research, 88-96. Ithaca and London: Comstock Publishing Associates.

Clary, E.G. and Snyder, M., 1999. The motivations to volunteer: Theoretical and practical considerations. Current Directions in Psychological Science, 8(5): 156-159. DOI: https://doi.org/10.1111/1467-8721.00037

Cnaan, R.A. and Amrofell, L.M., 1995. Mapping volunteer activity. Nonprofit and Voluntary Sector Quarterly, 23: 335-351. DOI: https://doi. org/10.1177/089976409402300404

Davis Smith, J., Ellis, A. and Brewis, G., 2005. CrossNational Volunteering: A Developing Movement? In: Brudney (ed.), Emerging Areas of Volunteering, 63-75. Indianapolis: ARNOVA.

Dunn, J., Chambers, S.K. and Hyde, M.K., 2016. Systematic Review of Motives for Episodic Volunteering. Voluntas, 27: 425-464. DOI: https://doi.org/10.1007/s11266015-9548-4

Dytham, C., 2011. Choosing and using statistics: A biologist's guide. 3rd Edition, Oxford: Blackwell Publishing.

Fielding, A.H., 2007. Cluster and Classification Techniques for the Biosciences. Cambridge: Cambridge University Press.

Garrett, C., 2011. Defining, detecting, and promoting student engagement in college learning environments. Teaching and Learning Journal, 5(2): 1-12.

Grey, F., 2009. The age of Citizen Cyberscience, 29 April 2009. Available at: https://cerncourier.com/cws/article/cern/387118 [Last accessed 1 July 2011].

Haklay, M., 2016. Why is Particpation Inequality important? In: Capineri, et al. (eds.), European handbook on crowdsourced geographic information, 35-45. London: Ubiquity Press.

Hennig, C., 2015. fpc: Flexible Procedures for Clustering. R package version 2.1-10.

Holmes, K., 2014. 'It fitted in with our lifestyle': An investigation into episodic volunteering in the tourism sector. Annals of Leisure Research, 17(4): 443-459. DOI: https://doi.org/10.1080/11745398.2014.965183

Hustinx, L. and Lammertyn, F., 2003. Collective and Reflexive Styles of Volunteering: A Sociological Modernization Perspective. Voluntas, 14(2): 167-187. DOI: https://doi.org/10.1023/A:1023948027200

Hyde, M.K., Dunn, J., Bax, C. and Chambers, S.K., 2016. Episodic Volunteering and Retention: An Integrated Theoretical Approach. Nonprofit and Voluntary Sector Quarterly, 45(1): 45-63. DOI: https://doi. org/10.1177/0899764014558934

Kahn, W.A., 1990. Psychological conditions of personal engagement and disengagement at work. Academy of
Management Journal, 33(4): 692-724. DOI: https:// doi.org/10.2307/256287

Liu, J. and Ram, S., 2011. Who does what: Collaboration patterns in the Wikipedia and their impact on article quality. ACM Transactions on Management Information Systems, 2(2): 11. DOI: https://doi. org/10.1145/1985347.1985352

Macduff, N., 2005. Societal Changes and the Rise of the Episodic Volunteer. In: Brudney (ed.), Emerging Areas of Volunteering. Indianapolis: ARNOVA.

Maechler, M., Rousseeuw, P., Struyf, A., Hubert, M. and Hornik, K., 2015. Cluster: Cluster analysis basics and extensions.

Maslach, C., 2011. Engagement research: Some thoughts from a burnout perspective. European Journal of Work and Organizational Psychology, 20(1): 47-52. DOI: https://doi.org/10.1080/13594 32X.2010.537034

Mohan, J. and Bulloch, S.L., 2012. The idea of a 'civic core': What are the overlaps between Charitable Giving, Volunteering, and Civic Participation in England and Wales. Third Sector Research Centre Working Paper, 73: $1-21$.

Neis, P. and Zipf, A., 2012. Analyzing the contributor activity of a Volunteered Geographic Information Project - The case of OpenStreetMap. International Journal of Geographic Information, 1: 146-165. DOI: https://doi.org/10.3390/ijgi1020146

Newmann, F.M., 1992. Student engagement and achievement in American secondary schools. New York: Teacher's College Press.

Nicoară, P-.S. and Haidu, I., 2014. A GIS based network analysis for the identification of shortest route access to emergency medical facilities. Geographia Technica, 9(2): 60-67.

Nielsen, J., 2006. Participation Inequality: Encouraging more users to contribute, 9 October 2006. Available at: https://www.nngroup.com/articles/participationinequality/ [Last accessed 3 May 2016].

Nov, O., Arazy, O. and Anderson, D., 2011. TechnologyMediated Citizen Science Participation: A Motivational Model. In: Proceedings of the Fifth International AAAI Conference on Weblogs and Social Media. Barcelona, Spain on 17-21 July 2011.

O'Brien, L., Townsend, M. and Ebden, M., 2008. Environmental volunteering: Motivations, barriers and benefits. Surrey: Forestry Commission.

Ponciano, L. and Brasileiro, F., 2014. Discovering Volunteers Engagement Profiles and Assessing their Implications for Human Computation Systems. Human Computation, 1: 5-28. DOI: https://doi.org/10.15346/ hc.v1i2.12

Ponciano, L., Brasileiro, F., Simpson, R. and Smith, A., 2014. Volunteers' Engagement in Human Computation Astronomy Project. Computing in Science and Engineering. DOI: https://doi.org/10.1109/ MCSE.2014.4

Pope, J., 2005. Volunteering in Victoria over 2004. Australian Journal on Volunteering, 10(2): 29-34. 
R Core Team. 2014. R: A language and environment for statistical computing, 29 October 2014. Available at: https://R-project.org [Last accessed 3 May 2016].

Reed, P.B. and Selbee, L.K., 2001. The civic core in Canada: Disproportionality in charitable giving, volunteering, and civic participation. Nonprofit and Voluntary Sector Quarterly, 30(4): 761-780. DOI: https://doi. org/10.1177/0899764001304008

Rochester, C., 2006. Making Sense of Volunteering: A literature review. London: The Commission on the Future of Volunteering.

Rousseeuw, P.J., 1987 Silhouettes: a graphical aid to the interpretation and validation of cluster analysis. Journal of Computational and Applied Mathematics, 20: 53-65. DOI: https://doi.org/10.1016/03770427(87)90125-7

Roy, H.E., Pocock, M.J.O., Preston, C.D., Roy, D.B., Savage, J., Tweddle, J.C. and Robinson, L.D., 2012. Understanding citizen science and environmental monitoring: final report on behalf of UK-EOF. NERC Centre for Ecology \& Hydrology and Natural History Museum.

Ryan, R.L., Kaplan, R. and Grese, R.E., 2001. Predicting Volunteer Commitment in Environmental Stewardship Programmes. Journal of Environmental Planning and Management, 44(5): 629-648. DOI: https://doi. org/10.1080/09640560120079948
Silvertown, J., Harvey, M., Greenwood, R., Dodd, M., Rosewell, J., Rebelo, T., Ansine, J. and McConway, K., 2015. Crowdsourcing the identification of organisms: A case-study of iSpot. ZooKeys, 480: 125-146. DOI: https://doi.org/10.3897/zookeys.480.8803

Stryker, S., 1980. Symbolic interaction: A social structural version. Menlo Park, CA: Benjamin Cummings.

Tulloch, A.I. and Szabo, J.K., 2012. A behavioural ecology approach to understand volunteer surveying for citizen science datasets. Emu, 112(4): 313-325. DOI: https://doi.org/10.1071/MU12009

Wagstaff, K., Cardie, C., Rogers, S. and Schoedl, S., 2001. Constrained K-means Clustering with Background Knowledge. In: Proceedings of the Eighteenth International Conference on Machine Learning, 577-584. Williamston, MA, USA.

Willems, J. and Walk, M., 2013. Assigning volunteer tasks: The relation between task preferences and functional motives of youth volunteers. Children and Youth Services Review, 35: 1020-1040. DOI: https://doi. org/10.1016/j.childyouth.2013.03.010

Zhu, A.D., Ma, H., Xiao, X., Luo, S., Tang, Y. and Zhou, S., 2013. Shortest Path and Distance Queries on Road Networks: Towards Bridging Theory and Practice. In: Proceedings of the 2013 ACM SIGMOD International Conference on Management of Data, 857-868. New York, USA on June 132013.

How to cite this article: Seymour, V and Haklay, M 2017 Exploring Engagement Characteristics and Behaviours of Environmental Volunteers. Citizen Science: Theory and Practice, 2(1): 5, pp.1-13, DOl: https://doi.org/10.5334/cstp.66

Submitted: 14 May 2016 Accepted: 09 February 2017 Published: 24 August 2017

Copyright: ( 2017 The Author(s). This is an open-access article distributed under the terms of the Creative Commons Attribution 4.0 International License (CC-BY 4.0), which permits unrestricted use, distribution, and reproduction in any medium, provided the original author and source are credited. See https://creativecommons.org/licenses/by/4.0/.

$\mathrm{u}[\quad$ Citizen Science: Theory and Practice is a peer-reviewed open access journal published by Ubiquity Press. 